\title{
Seroprevalence of caprine brucellosis in Karnataka
}

\author{
D. Avinash Reddy ${ }^{1}$, Gita Kumari², S. Rajagunalan ${ }^{3}$, D. K. Singh ${ }^{4}$, Ashok Kumar $^{5}$ and P. Pavan Kumar
}

Division of Veterinary Public Health, Indian Veterinary Research Institute, Izatnagar, Bareilly, Uttar Pradesh-243122, India

Corresponding author: D. Avinash Reddy, email: avi.incredible@gmail.com

1. avi.incredible@gmail.com, 2.drgita.kumari@rediffmail.com, 3.drgunavet@gmail.com, 4. dks_bly@yahoo.com, 5. ashokakt@rediffmail.com, 6. pavaa85@gmail.com

Received: 12-02-2014, Revised: 04-03-2014, Accepted: 08-03-2014, Published online: 28-03-2014

doi: $10.14202 /$ vetworld.2014.182-188

How to cite this article: Avinash Reddy D, Kumari G, Rajagunalan S, Singh DK, Kumar A and Pavan Kumar P (2014) Seroprevalence of caprine brucellosis in Karnataka, Veterinary World 7(3): 182-188.

\begin{abstract}
Aim: To study the seroprevalence of caprine bruellosis in Karnataka and compare the relative sensitivity and specificity among the different serological tests used.

Materials and Methods: A total of 252 serum samples were collected from the goats of Karnataka and subjected to 5 different serological tests, i.e., Rose Bengal Plate Test (RBPT), Standard Tube Agglutination Test (STAT), 2-mercaptoethanol test (2MET), Indirect ELISA(I-ELISA) and Dot-ELISA to detect the Brucella antibodies.

Results: Test-wise, the seroprevalence in goats was $5.15 \%$ by RBPT, $6.34 \%$ by STAT, $1.98 \%$ by 2 -MET, $9.52 \%$ by I-ELISA and $7.14 \%$ by Dot-ELISA. The prevalence of brucellosis was found to be highest among goats of northeast Karnataka followed by northwest Karnataka, central Karnataka and south Karnataka. I-ELISA detected maximum number of positive samples.
\end{abstract}

Conclusions: The study used five serological tests to determine the apparent seroprevalence of caprine brucellosis in Karnataka. Taking I-ELISA as reference, the tests revealed the relative sensitivity values in the following order: DotELISA $>$ STAT $>$ RBPT $>2$-MET.

Keywords: brucellosis, caprine, Karnataka, relative sensitivity, seroprevalence.

\section{I ntroduction}

Brucellosis is a major bacterial zoonosis of global, economic and public health significance, which poses a serious threat to the livestock economy. Brucellosis has shown a wide prevalence among livestock population all over the world. Caprine brucellosis due to Brucella melitensis which is widespread in India is a major cause of abortion in goats and also accounts for large number of human brucellosis cases [1, 2], the source of infection for man being occupational exposure during handling of unconfirmed cases of abortions and consumption of goat milk containing $B$. melitensis [3]. The most incontrovertible method of diagnosis for brucellosis is by isolation and identification [4] of the organism though it has some limitations like low sensitivity, health risk to laboratory personnel, time of sample collection and type of sample collected. As a result, recourse is taken in serological tests. A large number of serological tests are available for diagnosis of brucellosis of which Rose Bengal Plate Test (RBPT), Standard Tube Agglutination Test (STAT) and Complement Fixation Test (CFT) have been used extensively to diagnose brucellosis in animals. In humans, $90 \%$ of the brucellosis cases are said to be associated with $B$. melitensis due to its high virulence

Copyright: The authors. This article is an open access article licensed under the terms of the Creative Commons Attribution License (http://creativecommons.org/licenses/by/2.0) which permits unrestricted use, distribution and reproduction in any medium, provided the work is properly cited. as compared to B. abortus [3]. In India, goats have been reported to account for the transmission of brucellosis to maximum number of human cases and also caprine brucellosis is shown to be endemic [5].

Brucellosis in goats has been reported from various parts of the country including Karnataka [6]. In Karnataka, goat husbandry is extensively practiced. Based on the available literature with respect to prevalence of brucellosis in Karnataka, though caprine brucellosis was found in discrete parts of the state, no individual study encompassing all the four regions of Karnataka is attempted yet.

Thus the present study aimed to apply multiple tests like RBPT, STAT, MET, I-ELISA and Dot-ELISA to determine the apparent prevalence of caprine brucellosis in Karnataka and compare the relative sensitivities and specificities among the different tests applied.

\section{Materials and Methods}

Ethical approval: The study was conducted after the approval of the Institutional Animal Ethics Committee.

Samples: A total of 252 goat sera samples were collected from different parts of Karnataka having a history of various gynecological disorders like abortion, retention of placenta (R.O.P.), endometritis, infertility and repeat breeding. The samples were stored at $-20^{\circ} \mathrm{C}$ until they were used. All the serum samples were subjected to 5 serological tests, i.e., RBPT, STAT, 2MET, I-ELISA and Dot-ELISA to identify the presence 


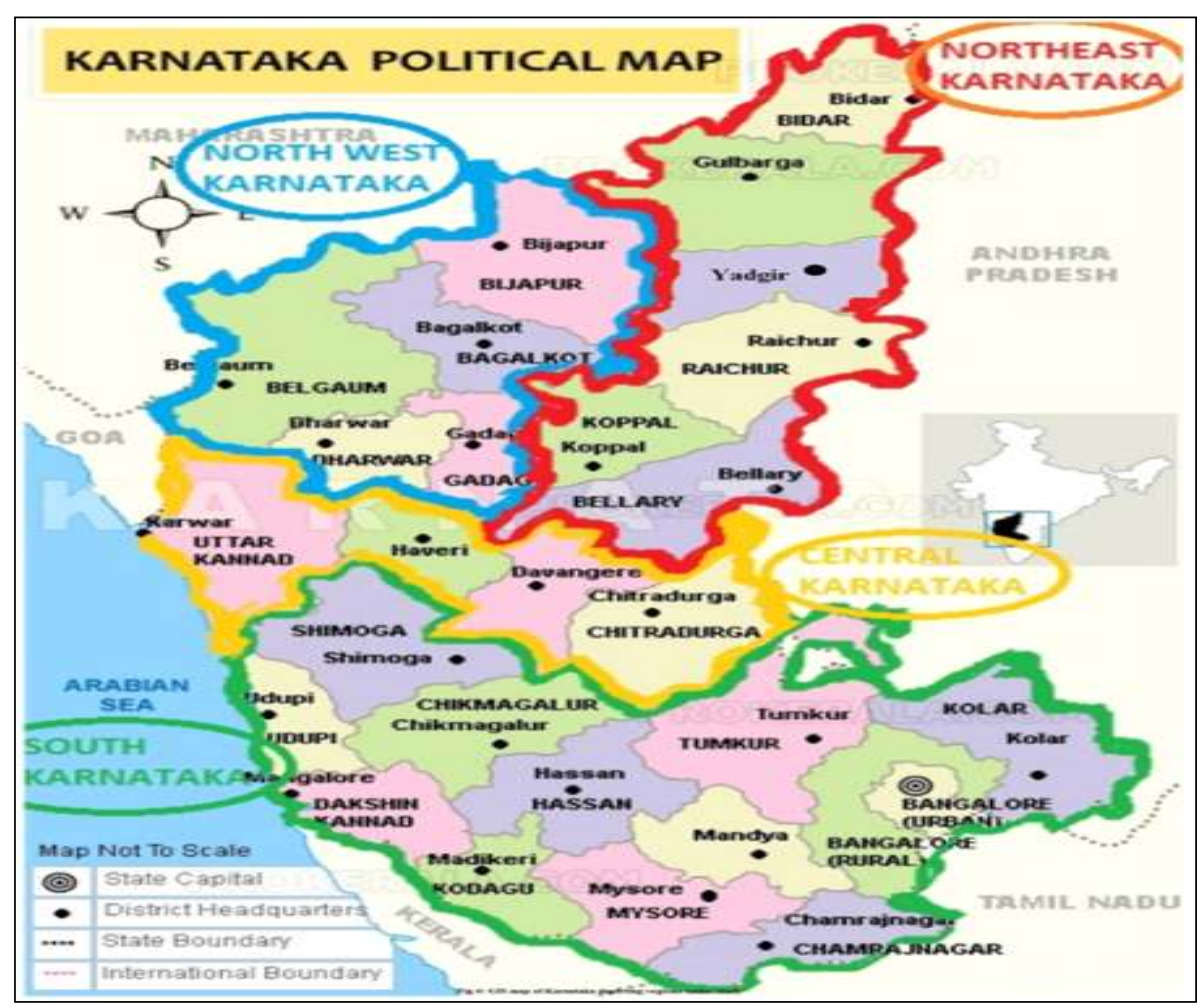

Figure-1: Map of study area

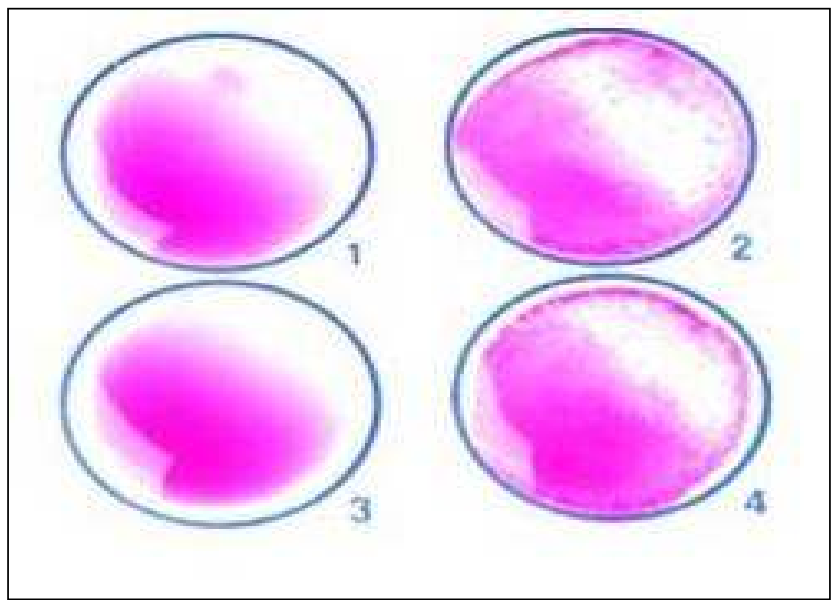

Figure-2: Rose Bengal Precipitation Test; 1 and 3 Negative, 2 and 4 positive

of Brucella antibodies.

RBPT, STAT and 2-MET: The colored antigen for RBPT and B. abortus plain antigen for STAT and 2-MET were procured from Biological Products Division, Indian Veterinary Research Institute (IVRI), Izatnagar. The RBPT, STAT and 2-MET were performed as described by Alton et al. [8]. Appearance of agglutination within 4 min of mixing of antigen and serum was considered as positive while absence of agglutination was recorded as a negative result for RBPT (Figure-2). For STAT (Figure-3) and 2-MET (Figure-4), the samples showing $\geq 50 \%$ agglutination at a dilution of $\geq 1: 20$ (40 I.U.) were considered positive.

I-ELI SA: The ELISA [9] was performed using smooth lipopolysaccharide (S-LPS) extracted from B. abortus S 99. S-LPS was extracted from heat-killed cells of $B$.

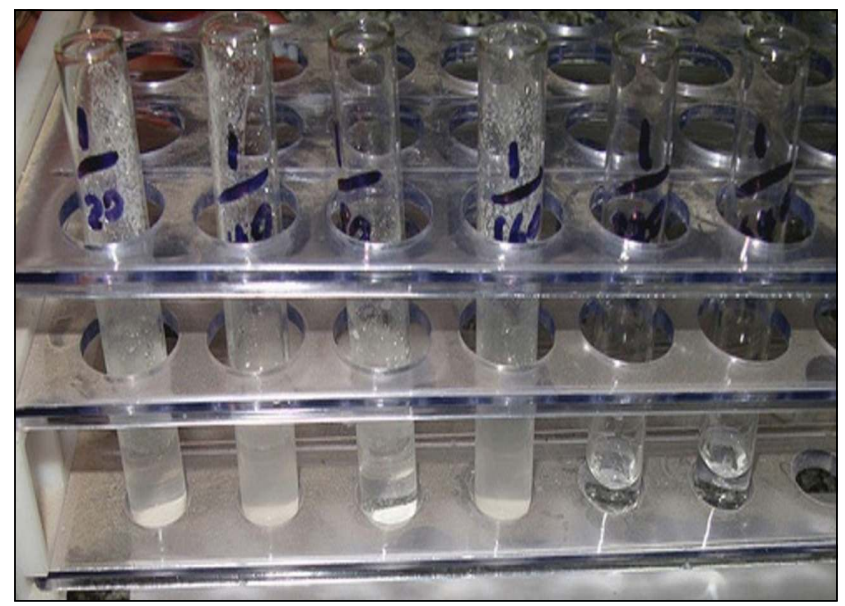

Figure-3: Standard Tube Agglutination Test

abortus, by the hot water/hot phenol method as described by OIE with minor modifications [10]. For the extraction, $5 \mathrm{~g}$ of lyophilized cells of $B$. abortus strain 99 was suspended in $170 \mathrm{ml}$ of distilled water (DW) and heated to $66^{\circ} \mathrm{C}$. An equal volume of phenol $(90 \% \mathrm{v} / \mathrm{v})$ in $\mathrm{DW}$, also heated to $66^{\circ} \mathrm{C}$, was added and the solution was stirred continuously for $20 \mathrm{~min}$. It was then cooled to $4^{\circ} \mathrm{C}$ and centrifuged at $12,000 \mathrm{~g}$ for 20 $\min$ at $4^{\circ} \mathrm{C}$. The phenol phase (bottom layer) was recovered and filtered through Whatman \#1 to which three volumes of chilled methanol reagent was added. It was mixed thoroughly and left to precipi-tate at $4^{\circ} \mathrm{C}$ for $2 \mathrm{~h}$. The precipitate was recovered by centrifugation at $12,000 \mathrm{~g}$ at $4^{\circ} \mathrm{C}$ and resuspended in the $80 \mathrm{ml}$ of DW and centrifuged at $6,000 \mathrm{~g}$ for $20 \mathrm{~min}$. The pellet was resuspended in $80 \mathrm{ml}$ of DW and stirred at $4^{\circ} \mathrm{C}$ overnight. The solution was then centrifuged at $10,000 \mathrm{~g}$ 


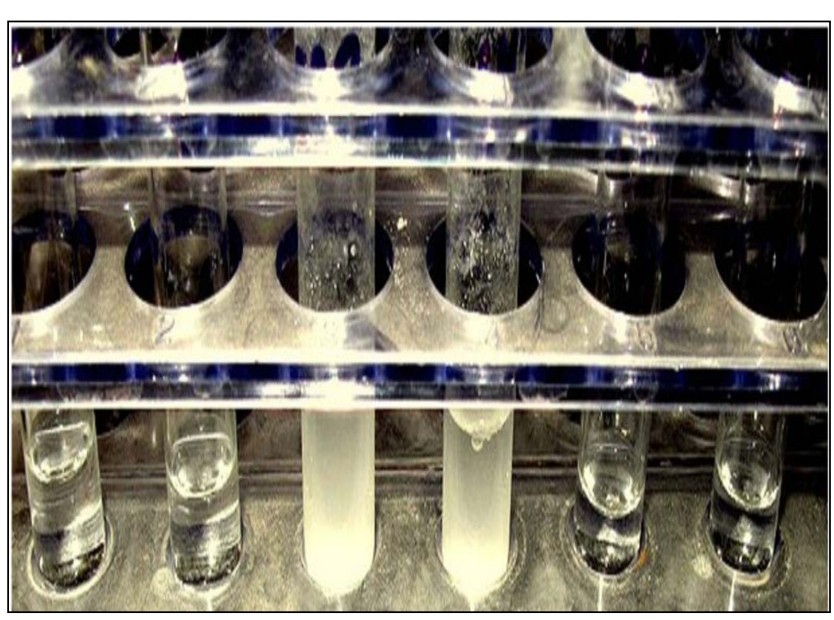

Figure-4: 2-Mercaptoethanol test

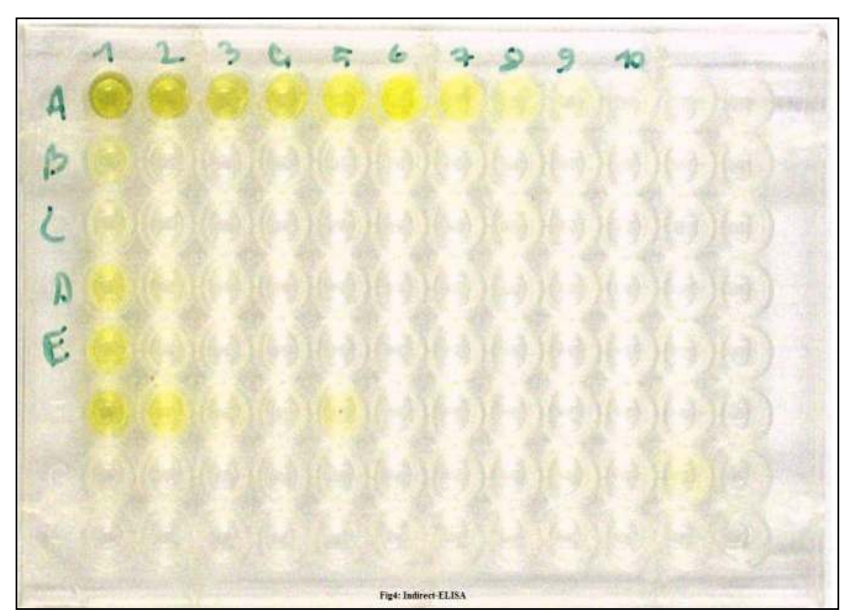

Figure-5: Indirect ELISA

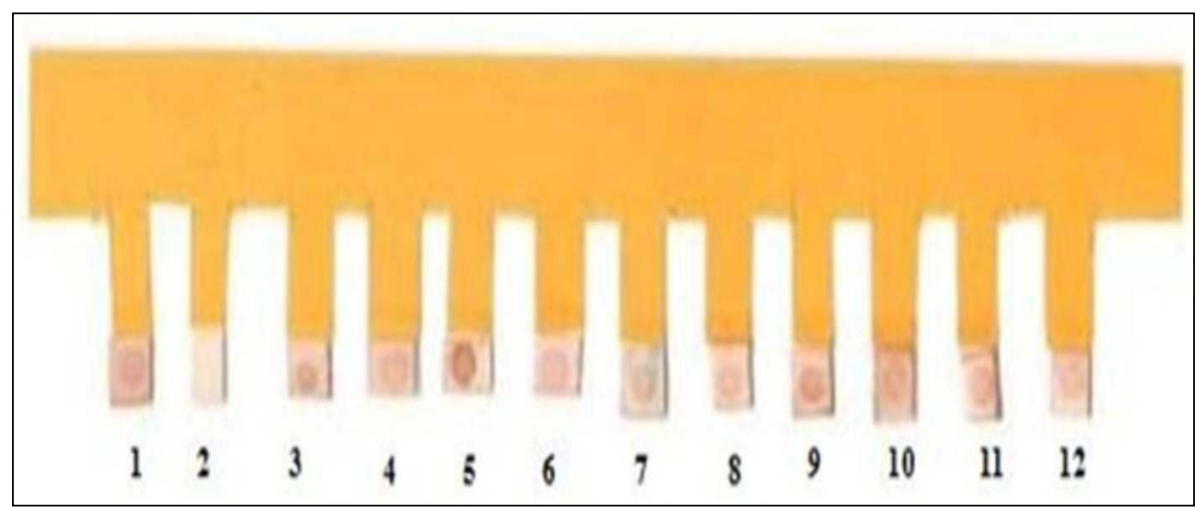

Figure-6: Dot-ELISA, 1: Positive control, 2: Negative control, 3-12: Representative positive samples

for $15 \mathrm{~min}$ at $4^{\circ} \mathrm{C}$ and the supernatant was decanted. Another $80 \mathrm{ml}$ of DW was added to the pellet, which was then stirred for $1 \mathrm{~h}$ and centrifuged as before. The two supernatant were pooled, filtered through membrane filter $(0.3 \mathrm{~mm})$, and $50-100 \mathrm{mg}$ each of ribonuclease, deoxyribonuclease and proteinase $\mathrm{K}$ were added. This mixture was incubated for $18 \mathrm{~h}$ at $20^{\circ} \mathrm{C}$. It was re-precipitated with methanol and resuspended as above in $2 \mathrm{ml}$ of DW. The solution was dialyzed extensively against DW until free of phenol. The resultant antigen was lyophilized, weighed and resuspended in DW to give $1 \mathrm{mg}$ LPS $/ \mathrm{ml}$. This was finally freeze dried in $1 \mathrm{ml}$ volume and stored at $4^{\circ} \mathrm{C}$ for future use. The LPS so obtained by above method was further dissolved at the concentration of $1 \mathrm{mg} / 3 \mathrm{ml}$ in sterilized $\mathrm{DW}$, aliquoted in $200 \mu \mathrm{l}$ volume and stored at $-20^{\circ} \mathrm{C}$. This was treated as the stock solution. For testing, the LPS stock solution was thawed and vortexed. A $10 \mu$ l of stock LPS was dispensed into the $10 \mathrm{ml}$ coating buffer (carbonate/bicarbonate buffer; pH-9.6), vortexed and $100 \mu \mathrm{l}$ per well was dispensed in flat bottom microtitre plates (Nunc). The plates were then incubated at $4^{\circ} \mathrm{C}$ overnight. Next day, the plates were washed thrice using the phosphate buffered saline (PBS; $0.01 \mathrm{M} ; \mathrm{pH}-$ 7.4) containing $0.05 \%$ Tween-20 (PBS-T). Before the final wash, 1:200 dilution of each test serum sample and control serum was prepared. After final wash, 100 $\mu l$ of each diluted serum was dispensed in the microtitre plates in duplicate wells and incubated for $1 \mathrm{~h}$ at $37^{\circ} \mathrm{C}$.
At the end of incubation, the plates were washed thrice with PBS-T as before and $100 \mu \mathrm{l}$ of working dilution of anti-species conjugate (Bangalore Genei) tagged with HRPO (1:8000 for goat) was dispensed in each well and the plates were incubated at $37^{\circ} \mathrm{C}$ for $1 \mathrm{~h}$. The plates were washed thrice with PBS-T as earlier. After last wash, $100 \mu \mathrm{l}$ of substrate solution containing $6 \mathrm{mg}$ orthophenyl-diamine (OPD) (Sigma) and $4 \mu 1$ of $\mathrm{H}_{2} \mathrm{O}_{2}$ $(30 \%)$ in $10 \mathrm{ml}$ of substrate buffer (Citrate buffer; $\mathrm{pH}-$ 4.5) was dispensed in each well. Plates were kept in dark for 15 min for color development. After $15 \mathrm{~min}$, the reaction was stopped by adding $50 \mu \mathrm{l}$ of $3 \mathrm{M} \mathrm{H}_{2} \mathrm{SO}_{4}$ and absorbance was measured at $492 \mathrm{~nm}$ in an ELISA reader (MICROSCAN MS5605A9). In each microtitre plate, strong positive, moderate positive, negative and conjugate controls were included (Figure-5). The optical density (OD) of strong positive control (absorbance value between 1.000 and 1.500) was used to calculate the percent positivity (PP) value for test samples using the following equation: $\mathrm{PP}=$ (absorbance of test sample/absorbance of strong positive control) $\times 100$. Serum sample having PP value $\geq 62$ in goats was taken as positive. A cut-off value of 62 was determined based on the results of the analysis of the mean and standard deviation (SD) of the total negative population in the study. The mean of the test values from uninfected animals $+2 \mathrm{SD}$ was used as the rationale in deciding the cut-off for the I-ELISA [11]. 
Table-1: Prevalence rates by different serological tests

\begin{tabular}{lcc}
\hline Tests & Positives & Prevalence (\%) \\
\hline RBPT & 13 & 5.15 \\
STAT & 16 & 6.34 \\
2-MET & 5 & 1.98 \\
I-ELISA & 24 & 9.52 \\
Dot-ELISA & 18 & 7.14 \\
\hline
\end{tabular}

Table-3: Relative sensitivity and specificity with I-ELISA as reference

\begin{tabular}{lcc}
\hline Tests & Relative sensitivity (\%) & Relative specificity (\%) \\
\hline RBPT & 54.16 & 100.00 \\
STAT & 66.66 & 100.00 \\
2-MET & 20.82 & 100.00 \\
Dot-ELISA & 75.00 & 100.00 \\
\hline
\end{tabular}

Table-2: Prevalence using combination of different tests

\begin{tabular}{lcccccc}
\hline Tests & $\mathbf{1}$ & $\mathbf{2}$ & $\mathbf{3}$ & $\mathbf{4}$ & $\mathbf{5}$ & $\mathbf{6}$ \\
\hline RBPT & - & - & - & - & + & + \\
STAT & - & - & - & + & + & + \\
2MET & - & - & - & - & - & + \\
I-ELISA & - & + & + & + & + & + \\
Dot-ELISA & - & - & + & + & + & + \\
Total $(\mathbf{n}=252)$ & 230 & 5 & 2 & 2 & 8 & 5 \\
\hline
\end{tabular}

1. A combination where 230 samples are negative to all the five tests. 2. A combination where 5 samples are positive only to I-ELISA but negative to rest of the four tests. 3. A combination where 2 samples are positive only to I-ELISA and Dot-ELISA but negative to remaining three tests. 4. A combination where 2 samples are positive to IELISA, Dot-ELISA and STAT but negative to remaining two tests. 5. A combination where among the five tests, 8 samples are positive to four tests but negative only to 2 -MET. 6. A combination where only 5 samples are positive to all the five tests.

Table-4: Seroprevalence of brucellosis among goats $(n=252)$ in different regions of Karnataka

\begin{tabular}{|c|c|c|c|c|c|c|c|c|c|c|}
\hline \multirow{2}{*}{$\begin{array}{l}\text { Region } \\
\text { (No.samples) }\end{array}$} & \multicolumn{2}{|c|}{ RBPT } & \multicolumn{2}{|c|}{ STAT } & \multicolumn{2}{|c|}{ 2-MET } & \multicolumn{2}{|c|}{ I-ELISA } & \multicolumn{2}{|c|}{ Dot-ELISA } \\
\hline & $+(\%)$ & $-(\%)$ & $+(\%)$ & $-(\%)$ & $+(\%)$ & $-(\%)$ & $+(\%)$ & $-(\%)$ & $+(\%)$ & $-(\%)$ \\
\hline \multicolumn{11}{|l|}{ Northeast } \\
\hline Karnataka (110) & $6(5.45)$ & $104(94.55)$ & $7(6.30)$ & 103(93.70) & $3(2.70)$ & 107(97.30) & $12(10.90)$ & $98(89.10)$ & $10(9.09)$ & $102(92.73)$ \\
\hline Karnataka (80) & $4(500)$ & $76(9500)$ & $4(500)$ & $76(9500)$ & $1(125)$ & $79(9875)$ & $8(1000)$ & 72(9000) & $5(6,25)$ & $75)$ \\
\hline Central & & $10(95.00)$ & $4(3.00)$ & $10(95.00)$ & $1(1.25)$ & $19(90.15)$ & $0(10.00)$ & $1<(90.00)$ & $5(0 . \angle 5)$ & $15(90.15)$ \\
\hline Karnataka (22) & $1(4.50)$ & $21(95.50)$ & $2(9.00)$ & $20(91.00)$ & $0(0)$ & $22(100.00)$ & $2(9.09)$ & $20(90.91)$ & $1(4.50)$ & $21(95.50)$ \\
\hline \multicolumn{11}{|l|}{ South } \\
\hline Karnataka (40) & $2(5.00)$ & 38(95.00) & $3(7.50)$ & $37(92.50)$ & $1(2.50)$ & $39(97.50)$ & $2(5.00)$ & $38(95.00)$ & $2(5.00)$ & $38(95.00)$ \\
\hline Total $(n=252)$ & $13(5.15)$ & $239(94.85)$ & $16(6.34)$ & $236(93.66)$ & $5(1.98)$ & $247(98.02)$ & $24(9.52)$ & $228(90.48)$ & $18(7.14)$ & $234(92.86)$ \\
\hline
\end{tabular}

Dot-ELISA: The test was performed as described by Sharma et al. [12]. LPS was dissolved at the concentration of $1 \mathrm{mg} / 1 \mathrm{ml}$ in sterilized DW and was stored at $20^{\circ} \mathrm{C}$. This was considered as stock solution. For test proper, the LPS stock solution was thawed and vortexed. The optimal concentration of LPS antigen was determined by checker-board titration fixed to $62.5 \mathrm{ng} / \mu \mathrm{l}$ and accordingly $1 \mu \mathrm{l}$ of this antigen was coated onto the centre of the nitrocellulose membrane (NCM) strips. The strips were allowed to dry at $37^{\circ} \mathrm{C}$ for 2 hours. To block the unbound sites in the NCM, the strips were incubated with $5 \%$ skim milk powder at $37^{\circ}$ $\mathrm{C}$ for $2 \mathrm{~h}$. The blocked NCM strips were rinsed in PBS$\mathrm{T}$ for four times, dried and later, the strips were incubated in the serum samples $(1: 200)$ at the $37^{\circ} \mathrm{C}$ for 45 min. After incubation, NCM strips were washed with PBS-T for four times. Further, the NCM strips were incubated with anti-species conjugate tagged with HRPO (1: 2000) for $45 \mathrm{~min}$ at $37^{\circ} \mathrm{C}$. The plates were washed four times with PBS-T. After last wash, the NCM strips were dipped in substrate solution containing $6 \mathrm{mg}$ diaminobenzidine (DAB) (Sigma) and $4 \mu \mathrm{H}_{2} \mathrm{O}_{2}(30 \%)$ in $10 \mathrm{ml}$ of substrate buffer (Citrate buffer; $\mathrm{pH}-4.5$ ) for $5 \mathrm{~min}$. The reaction was terminated by washing NCM strips with distilled water. The NCM strips were air dried and reaction was observed for the development of a brown spot (Figure-6). Appearance of brown spot was taken as positive.

\section{Results}

Of the 252 goat sera samples, $13(5.15 \%)$ were positive to RBPT, $16(6.34 \%)$ to STAT, 5 to 2-MET $(1.98 \%), 24(9.52 \%)$ to I-ELISA and $18(7.14 \%)$ to
Dot-ELISA. I-ELISA detected maximum number of sera, i.e., $24(9.52 \%)$ as positive (Table-1). Interestingly, there were $5(1.98 \%)$ sera samples positive only to IELISA and negative in rest of tests, while $5(1.98 \%)$ samples were positive to all the 5 serological tests (Table-2). It can also be seen from table that $8(3.17 \%)$ sera samples were found positive to RBPT, STAT, IELISA and Dot-ELISA but negative to 2-MET. Further, $2(0.79 \%)$ samples were positive only to IELISA and Dot-ELISA. The regional prevalence of brucellosis was found to be highest among goats of northeast Karnataka and lowest in south Karnataka (Table-4). I-ELISA detected most number of Brucella positive goats in all the different geographical regions of Karnataka with highest prevalence in northeast Karnataka (10.90\%) followed by northwest Karnataka (10.00\%), central Karnataka (9.09\%) and south Karnataka $(5.00 \%)$. Overall, the prevalence of brucellosis in goats was lowest in central Karnataka based on all the tests employed. Taking I-ELISA as reference, the tests revealed the relative sensitivity values in order of DotELISA $>$ STAT $>$ RBPT $>2$-MET. The Dot-ELISA emerged as being more sensitive than RBPT, STAT and 2-MET with a relative sensitivity of $75 \%$. The 2 -MET showed least relative sensitivity of $20.82 \%$. The relative sensitivity of RBPT was $54.16 \%$ and that of STAT was $66.66 \%$. It is also interesting to note that all the four tests showed 100 percent specificity.

\section{Discussion}

The most incontrovertible diagnosis of brucellosis is made by bacteriological isolation which has drawbacks like low sensitivity, time consuming and 
cumbersome. At times, isolation is not possible even from known positive cases [3] because of many factors like slow growth and poor sensitivity. The low sensitivity for isolation is attributed to many factors like the individual laboratory practices, quantity of pathogen in clinical samples, stage of infection, use of antibiotics before diagnoses and the methods used for culturing and the cultured strain (B. melitensis is more readily cultured from clinical sample than $B$. abortus). As a result, recourse is taken in serological tests. A large number of serological tests are available for diagnosis of brucellosis of which RBPT, STAT and CFT have been used extensively to diagnose brucellosis in animals. The limitations of conventional serological tests for diagnosis of brucellosis have been highlighted earlier where it has been shown that culture positive animals were negative in STAT, RBPT and CFT [13]. On the other hand, culture positive animals negative by RBPT and CFT have been found positive by I-ELISA [14]. In the present study, I-ELISA was taken as reference and subsequently the relative sensitivities and specificities were estimated for different serological tests. I-ELISA was taken as reference because of the fact that I-ELISA has been reported to be highly sensitive and specific and it can be used for the determination of specific IgG, IgM and IgA Brucella antibodies in blood, serum and CSF [15]. Further, IELISA has been considered as gold standard test by many workers to compare the results of other tests in case of brucellosis [16]. The speed and ease with which the I-ELISA can be performed, the high sensitivity and specificity values and the use of an easily obtainable antigen make the indirect I-ELISA an excellent test for the diagnosis of brucellosis.

Of 252 goat sera samples analyzed, 5.15, 6.34, $1.98,9.52$, and $7.14 \%$ samples were positive to RBPT, STAT, 2-MET, I-ELISA and Dot-ELISA, respectively. In a national survey Isloor [17] reported a low prevalence of 2.2 per cent. But the prevalence was lower in the present study than that obtained by Sharma et al. [18] in Jammu with $7.73,10.22$ and $12.98 \%$ positive cases by RBPT, STAT and I-ELISA, respectively. A high prevalence of brucellosis in goats was recorded in the present study (Table-5) in northeast Karnataka where RBPT, STAT, 2-MET, Dot-ELISA and I-ELISA detected $5.45,6.3,2.7,9.09$ and $10.9 \%$, respectively. In terms of RBPT and STAT, the results were in accordance with that of Awati et al. [19] who reported an overall prevalence of $5.30 \%$ among goats in and around Bidar district of northeast Karnataka. In northwest Karnataka, the goats showed comparatively low prevalence where $5 \%$ samples were positive to RBPT and STAT, $1.25 \%$ to 2 -MET, $10 \%$ to I-ELISA and $6.25 \%$ to Dot-ELISA, respectively (Table-5). But the prevalence was higher than that obtained by Sripad et al. [20] who reported percent prevalence of 0,0 during 2007-08; 3.2, 2.8 during 2008-09; and 0, 0 during 2009-10 by RBPT and STAT, respectively, around Belgaum district of northwest Karnataka. In south Karnataka, RBPT, STAT, 2-
MET, I-ELISA and Dot-ELISA detected 5, 7.5, 2.5, 5 and $5 \%$ as positive, respectively (Table-5). But in contrary to the results obtained in our study in south Karnataka, Vivekananda et al. [21] reported a seroprevalence of $1.96 \%$ in Mandya district of south Karnataka by IELISA. The lowest seroprevalence was observed among goats of central Karnataka where only 1 (4.5\%) goat sample was positive to RBPT and Dot-ELISA while 2 (9\%) samples were positive to STAT and I-ELISA, respectively. None of the samples were positive to 2MET. The reported prevalence of brucellosis among goats of different regions showed wide variations which may be because of differences in the husbandry practices in the regions investigated. Extensive small scale unorganised goat farming, free grazing practices, frequent mixing of ? ocks of goats, trading of indiscriminate diseased goats between the farmers are some of the factors which contribute to the higher prevalence of brucellosis in northeast and northwest Karnataka. In contrary to this, intensive farming system, stall feeding or zero grazing practice, better kidding management practices are the some of the reasons for lower prevalence of brucellosis in central and south Karnataka.

In this study, LPS based I-ELISA was found to be more sensitive than RBPT and STAT. Most of the samples that tested positive by STAT and RBPT were also positive by I-ELISA. However, Ghodasara et al. [22] reported relative sensitivity lower than our studies. In contrast, Chakraborty et al. [23] found higher sensitivity of STAT $(88.61 \%)$ over RBPT $(56.96 \%)$ and higher specificity of the STAT $(98.59 \%)$ than that of RBPT $(96.77 \%)$. Similarly, Singh et al. [24] revealed sensitivity of RBPT (88.46\%) much higher than STAT (46.15\%) but many workers [25] reported a lower relative sensitivity for RBPT than STAT. The relative sensitivity of RBPT was $54.16 \%$ with $100 \%$ relative specificity. In a similar study by Maninder et al. [26], it was found that RBPT test was the least sensitive (67.74 $\%)$ and I-ELISA was the most sensitive $(93.55 \%)$ among goats. The results were comparable with that of Sharma et al. [27] who reported RBPT to be $67.85 \%$ sensitive and $99.51 \%$ specific. Moreover, Rajkhowa [28] has reported lower sensitivity for RBPT (33\%). Similarly, Ferreira et al. [29] has recorded $87.8 \%$ sensitivity in bacteriologically negative but suspected animals. Such lower sensitivity of RBPT in sheep and goats compared to cattle and buffaloes may be because of inadequate standardization conditions of RBPT antigen in relation to sheep and goats which is used to standardize against International Standard antiBrucella abortus serum (ISaBS) [30]. The 2-MET showed a very low relative sensitivity of $20.82 \%$ and a relative specificity of $100 \%$. This could be explained by the fact that the 2-MET measures IgG antibodies only, where as the other tests like STAT measure the total amount of agglutinating antibodies (IgM and $\operatorname{IgG})$. This differentiation is important, as IgG antibodies are considered better indicators of an active infection than IgM [31]. The Dot-ELISA emerged more sensitive 
than RBPT, STAT and 2-MET with a relative sensitivity of $75 \%$ and a relative specificity of $100 \%$. Our results were in accordance with Chachra et al. [32] who found Dot-ELISA to be the most sensitive $(100 \%)$ when compared to RBPT and STAT. Similarly, Barbuddhe et al. [33] also reported higher relative sensitivity and specificity values of $87.71 \%$ and $85.71 \%$, respectively for Dot-ELISA in comparison to CFT.

\section{Conclusion}

Thus, on the basis of the present study, we conclude that caprine brucellosis is fairly prevalent in the regions of Karnataka where samples were collected. The various tests have projected different levels of prevalence among the goat populations which is an outcome of sensitivity and specificity of the different tests. The study found that the prevalence of caprine brucellosis was highest in the region of northeast Karnataka followed by northwest Karnataka, central Karnataka and south Karnataka. I-ELISA has proved to be highly sensitive and specific test for diagnosing brucellosis in goats. However, this needs further evaluation using large number of serum samples preferably from animals of known status with respect to bacteriological isolation which yields most incontrovertible diagnosis of brucellosis. Eventually, to deal with occupation-related diseases like brucellosis, knowledge of risk factors is vital for control and prevention programmes. Thus, an extension education campaign, particularly in the high-risk areas, among veterinary practitioners and livestock owners, could aid in decreasing the incidence of brucellosis. In addition, regular surveillance of the disease needs to be integrated into control and prevention programmes at local and national levels. An integrated approach to disease surveillance involving both human health and veterinary services would allow a better understanding of disease dynamics at the animal-human interface, as well as a more cost-effective utilisation of the available resources.

\section{Authors' contributions}

The present study was a part of DAR's original research work during his M.V.Sc thesis programme. DKS conceptualized the aim of the study, designed, planned and supervised the experiment and corrected the manuscript. Collection of samples, execution of the experimental study, collation and analysis of data, interpretation of the results and drafting the manuscript was done by DAR. GK, SR, AK and PPK helped in analyses, draft and revision of the manuscript. All authors read and approved the final manuscript.

\section{Acknowledgements}

The authors are thankful to the Director, IVRI, Izatnagar and Head, Division of Veterinary Public Health, Indian Veterinary Research Institute, Izatnagar for providing facilities to carry out this work. IVRI institutional fellowship awarded to Avinash Reddy is also duly acknowledged.

\section{Competing interests}

The authors declare that they have no competing interests.

\section{References}

1. Mantur, B. G. and Amarnath, S. K. (2008) Brucellosis in India-a review, J. Biosci. 33: 539-547.

2. Awad, R. (1998) Human brucellosis in the Gaza Strip, Palestine, East. Mediterr. Health J. 4: 225-233.

3. Seleem M.N., Boyle S.M., Sriranganathan N. (2010) Brucellosis: A re-emerging zoonosis, Vet. Microbiol., 140: 392-398.

4. Boral, R., Singh, M. and Singh, D.K. (2009) Status and strategies for control of brucellosis- a review. Indian $J$. Anim.Sci., 79(12): 1191-1199.

5 Renukaradhya, G.J., Isloor, S. and Rajasekhar, M. (2002) Epidemiology, zoonotic aspects, vaccination and control/eradication of brucellosis in India. Vet. Microbiol., 90: 183-95.

6. Kumar, P., Singh, D.K. and Barbuddhe, S.B. (1997) Serological evidence of brucellosis in sheep and goats. Indian J. Anim. Sci., 67: 180-182.

7. Shome, R., Shome, B. R. and Desai, G.S. (2006) Seroprevalence of brucellosis in small ruminants. Indian J. Comp. Microbiol. Immunol. Infect. Dis. 27: 13-15.

8. Alton, G.G., Jones, L.M., Angus, R.D. and Verger, J.M. (1988) Techniques for the Brucellosis Laboratory. INRA, Paris.

9. Singh, R.K. (2009) Prevalence of brucellosis among ruminants and comparision of serological test. M.V.Sc. thesis submitted to Deemed University, IVRI, Izatnagar, India.

10. OIE (2008) Manual of diagnostic tests and vaccines. Bovine brucellosis, OIE, Paris, pp. 624- 659.

11. Jacobson R.H. (1998) Validation of serological assays for diagnosis of infectious diseases. In Veterinary laboratories for infectious diseases (J.E. Pearson, ed.). Rev. Sci. Tech. Off. int. Epiz., 17 (2): 469-486.

12. Sharma, R., Tuteja, U., Shukla, R.K.J. and Batra, H.V. (2007) Application of rapid dot-ELISA for antibody detection of leptospirosis. J. Med. Microbiol., 56: 873-874.

13. Herr, S., Roux, D. and Pieterson, P.M. (1982) The reproducibility of results in bovine brucellosis serology and their correlation with the isolation of Brucella abortus. Onderstepoort J. Vet. Res., 49: 79-83.

14. Sutherland, S.S., Evans, R. J. and Bathgate, J. (1986) Application of an enzyme linked immunosorbent assay in the final stages of a bovine brucellosis eradication program. Aust. Vet. J., 63: 412-415.

15. Araj, G.F. (1989) Profiles of Brucella-specific immunoglobuline $\mathrm{G}$ subclasses in sera of patients with acute and chronic brucellosis. Serodiagn Immunother Infect Dis., 2: 401-410.

16. Nielsen, K.H., Kelly, L., Gall, D., Balsevicus, S., Bosse, J., Nicolitti, P. and Kelly, W. (1996) Comparison of enzyme immunoassays for the diagnosis of bovine brucellosis. Prev. Vet. Med., 26: 17-32.

17. Isloor, S., Renukaradhya, G.J. and Rajasekhar, M. (1998) A serological survey of bovine brucellosis in India. Rev. Sci. Tech. Off. Int. Epizoot., 17: 781-785.

18. Sharma, H.K., Kotwal, S.K. and Singh, D.K. (2012) Comprehensive seroprevalence study of brucellosis in sheep and goats of Jammu. $11^{\text {th }}$ Annual conference of Indian Association of Veterinary Public Health Specialists (IAVPHS). One health: way forward to challenges in food safety and zoonoses in $21^{\text {st }}$ century, GADVASU, Ludhiana, December 13-14.

19. Awati, B., Chavhan, S. K., Hari Babu, Y. and Sundareshan, S. (2011) Seroprevalence of Brucellosis in Sheep and Goats in and around Bidar $25^{\text {th }}$ Annual Conference of IAVMI and International Conference on "Energizing Animal Health for Better Livestock Production Under WTO 
regime", Department of Veterinary Microbiology, Veterinary college, Bangalore, June 9-11, 2011

20. Sripad, K., Kowali, S., Venkatesha, P. and Renukaprasad, C. (2011) Prevalence of Brucellosis in and around Belgaum District in Karnataka by $25^{\text {th }}$ Annual Conference of IAVMI and International Conference on "Energizing Animal Health for Better Livestock Production Under WTO regime", Department of Veterinary Microbilogy, Veterinary college, Bangalore, June 9-11, 2011.

21. Vivekananda, Shome, R., Sheela, P., Balamurugan, Nagalingam, Veeresh, K. and Isloor, S. (2011) Seroprevalence Study of Brucellosis in Sheep in Mandya District Karnataka. 25 ${ }^{\text {th }}$ Annual Conference of IAVMI and International Conference on "Energizing Animal Health for Better Livestock Production Under WTO regime", Department of Veterinary Microbilogy, Veterinary college, Bangalore, June 9-11, 2011.

22. Ghodsara, S.N., Roy, A. and Bhanderi, B.B. (2010). Comparison of Rose Bengal Plate Agglutination, Standard tube agglutination and Indirect ELISA tests for detection of Brucella antibodies in Cows and Buffaloes. Vet. World, 3: 61-64.

23. Chakraborty, M., Patziri, G.P. and Sharma, D.K. (2000) Use of Rose Bengal plate test, serum agglutination test, I-ELISA for detecting brucellosis in bovines. Indian. J. Comp. Microbiol. Immunol. Infect. Dis., 21:24-25.

24. Singh, G., Sharma, D.R. and Dhand, N.K. (2004) Seroprevalence of bovine brucellosis in Punjab. Indian Vet. J., 81:620-623.

25. Brahmabhatt, M.N., Varasada, R.N., Bhong, C.D. and Nayak, J.B. (2009) Seroprevalence of brucella spp. in buffaloes in the central Gujarat region of India. Buffalo Bulletin, 28:73-75.
26. Singh, Maninder., Singh, D.K., Boral, Rupa., Kumari, Gita., Rawat, Shriya., Biswas, Ripan.(2011). Multitesting of brucellosis in small ruminants. Onl J Vet Res., 15(6): 468475.

27. Sharma, V.K., Savalia, C.V., Selvam, D.T. and Darekar, S.D. (2006) Seroprevalence of caprine and ovine brucellosis in Mehsana and Patan districts of Gujarat. Intas Polivet, 7: 316318.

28. Rajkhowa, S., Rahman, H., Rajkhowa. and Bujarbaruah, K.M. (2005) Seroprevalence of brucellosis in mithuns (Bos frontalis) in India. Prev. Vet. Med., 69: 145-151.

29. Ferreira, A.C., Cardoso, R., Travassos Dias, I., Mariano, I., Belo, A., Rolao Preto, I., Manteigas, A., Pina Fonseca, A.M. and Correa De Sa, M.I. (2003) Evaluation of a modified Rose Bengal test and an indirect enzyme-linked immunosorbent assay for the diagnosis of Brucella melitensis infection in sheep. Vet. Res., 34: 297-305.

30. Garin-Bastuji, B. and Blasco, J.M. (2004) Caprine and ovine brucellosis (excluding B. ovis). In: Manual of Diagnostic Tests and Vaccines for Terrestrial Animals, $5^{\text {th }}$ ed. OIE, pp. 598-606.

31. Buchanan, T.M. and Faber, L.C. (1980) 2-mercaptoethanol Brucella agglutination test: Usefulness for predicting recovery from brucellosis. J. Clin. Microbiol., 11:691-3.

32. Chachra, D., Saxena, H.M., Kaur, G. and Chandra, M. (2009) Comparative efficacy of Rose Bengal plate test, standard tube agglutination test and Dot ELISA in immunological detection of antibodies to Brucella abortus in sera. $J$. Bactriol. Res, 1:30-33.

33. Barbuddhe, S.B., Yadava, V.K. and Singh, D.K. (1994) Comparison of Dot-ELISA with conventional serological tests for diagnosing ovine brucellosis. Indian J. Comp. Microbiol. Immunol. Infect. Dis., 15: 1-5. 